\title{
Determination of temperature and water-concentration in fuel-rich oxy-fuel methane flames applying TDLAS
}

\author{
Matthias Martin Sentko ${ }^{\mathrm{a}, *}$, Sebastian Schulz ${ }^{\mathrm{a}}$, Björn Stelzner ${ }^{\mathrm{a}}$, Christopher Anderlohr ${ }^{\mathrm{b}}$, \\ Maximilian Vicari ${ }^{\mathrm{b}}$, Dimosthenis Trimis ${ }^{\mathrm{a}}$
}

a Engler-Bunte-Institute, Division of Combustion Technology, Karlsruhe Institute of Technology, Karlsruhe, Germany

${ }^{\mathrm{b}}$ BASF SE, Ludwigshafen, Germany

Keywords:

TDLAS

Oxy-fuel

Fuel-rich

Temperature

SAFT

\begin{abstract}
A B S T R A C T
Combustion processes with pure oxygen (oxy-fuel) instead of air as oxidant are attractive for high temperature thermal or thermochemical and gasification processes. The absence of nitrogen in such applications leads to higher temperature and species concentrations, which can stabilize even extremely rich flames. Despite their benefits, there is lack of knowledge concerning the internal structure of rich oxyfuel flames, which feature reactions with largely diverging chemical time scales, namely, the fast oxidation reactions and the slow endothermic formation of synthesis gas. In order to get a better insight, the scope of this study was to determine axial $\mathrm{H}_{2} \mathrm{O}$ - and temperature profiles of flat, fuel-rich methaneoxygen flames with equivalence ratios from $2.5 \leq \phi \leq 2.9$. A Heat-Flux-burner was used to stabilize quasi-adiabatic one-dimensional flames. The inlet temperature of the gas mixture was kept constant at $T_{P}=300 \mathrm{~K}$ and the inlet velocity equal to the laminar burning velocity, which was determined in a preceding experimental study. The in-situ temperature and $\mathrm{H}_{2} \mathrm{O}$-concentration measurements were performed using Tunable Diode Laser Absorption Spectroscopy (TDLAS). Laser measurements were carried out with three different diode lasers at center wavelengths $\lambda_{c w}=1344.5 \mathrm{~nm}, 1392.3 \mathrm{~nm}$ and $1853.5 \mathrm{~nm}$, respectively, where multiple absorption peaks of the water molecule were investigated. Additionally, onedimensional calculations with detailed chemistry were performed using the PREMIX code together with the GRI3.0 and CalTec2.3 mechanisms and compared with the experimental data. The results of the temperature measurements showed temperature peaks in the flame zone and a temperature decrease in the endothermic post flame zone, where synthesis gas is formed. The measured peak temperatures exceed the calculated equilibrium temperatures by approximately $100-400 \mathrm{~K}$ indicating super-adiabatic flame temperatures (SAFT). Both reaction mechanisms showed similar trends with respect to the decrease of the temperature in the post flame zone and were in line with the measured temperature. In contrast, the calculated decomposition of water in the post flame zone highly depends on the applied chemistry scheme. Here, the CalTech2.3 mechanism showed excellent performance in comparison to the experimental data for $\phi>2.5$. For $\phi=2.5$ the GRI3.0 performed better.
\end{abstract}

\section{Introduction}

Combustion processes with pure oxygen (oxy-fuel) instead of air as the oxidant are attractive e.g., for high temperature thermal or thermochemical and gasification processes. In such applications, the absence of nitrogen leads to many advantages such as improved flame characteristics, lower exhaust gas volumes, reduced costs, increased flexibility and improved product quality [1].

An example for the use of partial oxidation (POX) of methane is the production of high purity synthesis gas with a high amount of

\footnotetext{
* Corresponding author.

E-mail address: matthias.sentko@partner.kit.edu (M.M. Sentko).
}

hydrogen, which can subsequently be used in downstream synthesis processes, such as the Fischer-Tropsch or methanol synthesis.

In the case of such methane/oxygen flames (premixed, fuelrich in the equivalence ratio range of $2.5<\phi<3.0$ and without any dilution of the oxidizer) experimental data are scarce. Li et al. [2] measured temperatures and species concentrations in methane/oxygen flames in the equivalence ratio range of $3.08<$ $\phi<3.64$ using invasive measurement techniques (thermocouple and mass spectrometer) and showed temperature and water concentration profiles.

The determination of temperature and water concentration profiles in harsh environments (e.g., fuel-rich flames) is challenging because invasive measurements, such as thermocouple or gas 
sampling systems, have an effect on the flow field and disturb the flame. Furthermore, in the case of heavily sooting flames $(\phi>$ 2.5 ), soot deposition on the thermocouple has a strong impact on radiation correction (emissivity coefficient and wire diameter) and hence on the measured temperature. Additionally, soot deposition may easily clog the sampling probe and a large inlet diameter has to be chosen, which handicaps the rapid quenching of the sampled gas.

Tunable Diode Laser Absorption Spectroscopy (TDLAS) is an optical, in-situ, calibration free, integral (along the laser path) measurement technique. This technique is suitable for measuring species concentrations and temperature even under harsh flame conditions, since soot radiation affects only the signal-to-noise ratio (decreases) without imposing a systematic error. In literature TDLAS, in form of direct absorption (DA) or wavelength modulation spectroscopy (WMS), was applied for temperature measurements and species concentration at different burner setups ranging from lab scale burners [3-11] via pilot scale combustors [12-14] to industrial scale combustion chambers [15]. For the determination of temperature profiles, in addition to the water molecule detection [3,4,6,8-16] the carbon monoxide molecule [7] turned out to be a suitable and interference free marker in combustion environment.

The development of reaction mechanisms for very rich flames has turned out to be challenging [17] because chemical pathways with slow chemical time scales are activated and lead to the formation of higher hydrocarbons. Due to temperature conditions that are intrinsically different, from stoichiometric or lean conditions, time scales can differ significantly from those of high temperature oxidation reactions. Such effects are very prominent in ultra-rich oxy-fuel flames, where endothermic production of $\mathrm{H}_{2} / \mathrm{CO}$ rich synthesis gas takes place downstream of the flame front. The difference in the time scales of the fast oxidation reactions and the slow endothermic formation of synthesis gas leads to the so-called super adiabatic flame temperatures (SAFT) phenomena. In this case the peak temperature in the flame can exceed the equilibrium temperature by several hundred Kelvins. SAFT was first reported by Meeks et al. [18], when numerically investigating $\mathrm{C}_{2} \mathrm{H}_{2} / \mathrm{O}_{2} / \mathrm{H}_{2}-$ flames. Bertagnolli et al. $[19,20]$ experimentally determined SAFT for this type of flames. Liu et al. [21,22] showed the occurrence of SAFT in fuel-rich $(\phi=1.5) \mathrm{CH}_{4} / \mathrm{O}_{2}$-flames numerically, stating that SAFT strongly correlates to the local $\mathrm{H}_{2} \mathrm{O}$ overshot. Stelzner et al. [23] performed a numerical study for $\mathrm{CH}_{4} / \mathrm{O}_{2}$-flames over a wide range $(0.5<\phi<3.0)$, stating that the effect of SAFT increases with higher equivalence ratios $(\phi>2.1)$. Also here, the SAFT phenomenon in ultra-rich flames is induced by a local water overshoot compared to equilibrium. This fact makes the local temperature and $\mathrm{H}_{2} \mathrm{O}$-concentration promising markers for the global divergence of two chemical time scales; fast high temperature oxidation and slow endothermic synthesis gas production, respectively.

Scope of this study is the experimental determination of temperature and water concentration profiles in premixed laminar fuel-rich $\mathrm{CH}_{4} / \mathrm{O}_{2}$ flames using the in-situ measurement technique TDLAS, to get an experimental insight into fast oxidation and slow POX reactions in these flames. The acquired experimental data was used to extend the numerical results presented by Stelzner et al. [23].

\section{Fundamentals of TDLAS}

TDLAS is a laser-based, in-situ, integral (along the laser path) and calibration-free measurement technique for the determination of temperature and species concentration based on the Beer-Lambert law. The history, fundamentals and measurement techniques of TDLAS in combustion are described in great detail by e.g., Goldenstein et al. [24] and Bolshov et al. [25].
The measuring principle of TDLAS is based on change of the emitted wave number of the diode laser by modifying its temperature and the diode laser current. By adjusting the temperature of the diode laser, the emitted wavelength is roughly set to the center wavelength of the investigated range of wave numbers and kept constant afterwards. In a second step the range is scanned by modulating the diode laser current (up to $\mathrm{MHz}$ rates [26]) and therefore the emitted output power and wave number.

The optical density OD (Eq. (1)), given by rearranging the BeerLambert law, is used in the TDLAS measurement procedure to determine the species concentration.

$O D=-\ln \left(\frac{I(\tilde{v})}{I_{0}(\tilde{v})}\right)=S(T) \cdot f\left(\tilde{v} ; \tilde{v}_{0}, \gamma\right) \cdot N \cdot l_{a}$

with $S(T)$ denoting the spectral line intensity, $f$ the form function. In the case of a Lorentzian shape, $\tilde{v}_{0}$ describes the line position, $\gamma$ the line width, $N$ and $l_{a}$ the number of absorbers and the absorption length, respectively. The form function was normalized using $\int f(\tilde{v}) d \tilde{v}=1$. The spectral molecule data were taken from the HITRAN [27] and HITEMP [28] databases.

In this study, a multiline thermometry approach based on a Boltzmann plot analysis was used. This analysis technique is a basic tool for the determination of temperature and concentration using multiple absorption lines of a given molecule. The relevant equation results from the integration of the Beer-Lambert's law (Eq. (1)), including the temperature-dependent spectral line intensity $S(T)$ via the wave number. Neglecting the term of the stimulated emission leads to a linear dependency between the integrated area term and the lower energy state $E_{0}[29]$ :

$\ln \left(\frac{A}{S_{\text {ref }}} \exp \left(-\frac{c_{2} E_{0}}{T_{\text {ref }}}\right)\right)=a_{1} E_{0}+a_{0}$

Including the determined peak area $A$, lower energy state $E_{0}$, spectral line intensity $S_{\text {ref }}$ at reference temperature $T_{\text {ref }}$ and the second radiation constant $c_{2}$. The temperature $T$ is extracted from the slope of the linear fit $a_{1}$ :

$a_{1}=-\frac{c_{2}}{T}$

The $y$-intercept $a_{0}$ is used for determination of the number of absorbing molecules and therefore the volume concentration, using the knowledge of the absorption length:

$a_{0}=\ln \left(\frac{Q\left(T_{\text {ref }}\right)}{Q(T)} N l_{a}\right)$

where $Q$ is the partition function.

\section{Experimental setup and data analysis}

In this section, the experimental setup of the TDLAS diagnostic system (Section 3.1), the burner system (Section 3.2) and the data analysis of the measured TDLAS signal (Section 3.3) are explained in detail.

\subsection{TDLAS setup}

Over the spectral range from 0 to $30,000 \mathrm{~cm}^{-1}$ more than $10^{8}$ absorption lines of the water molecule are listed [28]. A thorough literature search showed, that for the determination of water concentration and temperature different absorption lines were used, e.g., $[4,8,16,29-32]$. In addition to the recommendations from the literature, several different criteria were used in order to identify the most suitable absorption lines. As the expected temperatures are in the range of $300-2500 \mathrm{~K}$, the spectral line intensity $S(T)$ has to be sufficiently large $\left(S(T)>5 \cdot 10^{-23}\right)$ in the given range. 
Table 1

Identified and used spectral lines of the $\mathrm{H}_{2} \mathrm{O}$ molecule for the Boltzmann plot.

\begin{tabular}{lllll}
\hline Diode laser & & $\begin{array}{l}\text { Peak } \\
\text { position } / \mathrm{cm}^{-1}\end{array}$ & $\begin{array}{l}\mathrm{S}(\mathrm{T}) \mathrm{at} \\
T_{\text {ref }} / \frac{\mathrm{cm} \mathrm{N}_{\mathrm{mol}} \mathrm{cm}{ }^{2}}{}\end{array}$ & $\begin{array}{l}\text { Lower-state } \\
\text { energy } / \mathrm{cm}^{-1}\end{array}$ \\
\hline $\mathrm{A}$ & 1 & 7444.35 & $2.178 \mathrm{e}-23$ & 1774.75 \\
& 2 & 7444.37 & $2.516 \mathrm{e}-23$ & 1806.67 \\
& 3 & 7447.48 & $8.956 \mathrm{e}-23$ & 1360.24 \\
$\mathrm{~B}$ & 4 & 7185.59 & $8.000 \mathrm{e}-22$ & 1045.05 \\
$\mathrm{C}$ & 5 & 5395.56 & $3.643 \mathrm{e}-23$ & 1789.04 \\
& 6 & 5398.47 & $1.226 \mathrm{e}-23$ & 1908.01 \\
& 7 & 5399.39 & $7.846 \mathrm{e}-26$ & 3032.69 \\
\hline
\end{tabular}

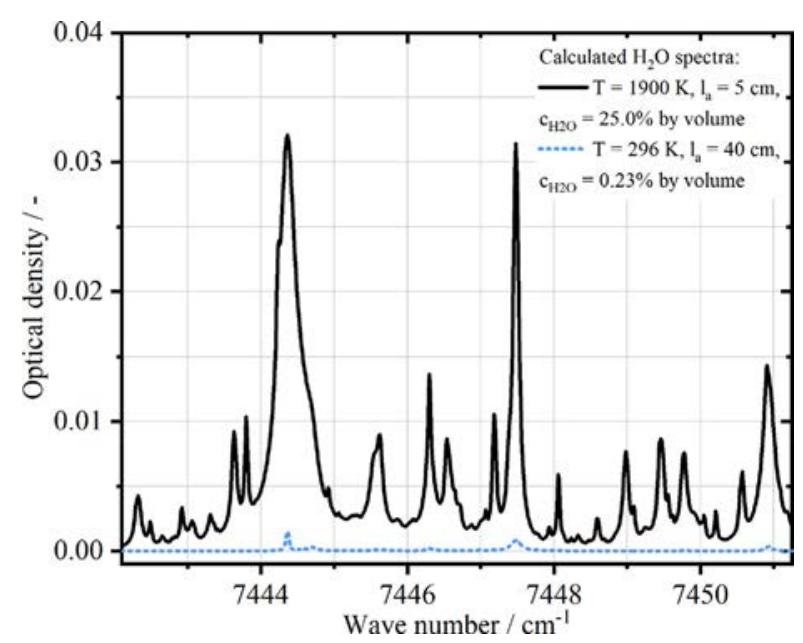

Fig. 1. Scanned wave number range of diode laser $A$, including calculated spectra at flame conditions ( $T=1900 \mathrm{~K}, l_{a}=5 \mathrm{~cm}$ and $c_{\mathrm{H}_{2} \mathrm{O}}=25 \%$ by volume) and ambient conditions ( $T=296 \mathrm{~K}, l_{a}=40 \mathrm{~cm}$ and $c_{\mathrm{H}_{2} \mathrm{O}}=0.23 \%$ by volume).

For the determination of water concentration, the temperature dependency $S(T) / T$ should be constant. Another important aspect is avoiding interference with the absorption spectra of other combustion products (e.g., $\mathrm{CO}, \mathrm{CO}_{2}$ ) and the spectral isolation to other water absorption peaks. As a result of this line selection process seven suitable $\mathrm{H}_{2} \mathrm{O}$ absorption peaks were identified (Table 1) and three different pigtailed diode laser (NanoPlus $\mathrm{GmbH}$ ), at center wavelengths of $1344.5 \mathrm{~nm}(\mathrm{~A}), 1392.3 \mathrm{~nm}$ (B) and $1853.5 \mathrm{~nm}$ (C), were used in the current study. The nominal output power produced by the diode laser is in the range of $3 \mathrm{~mW}$ to $5 \mathrm{~mW}$ and a line width of less than $3 \mathrm{MHz}$.

The diode laser current was modulated in the form of a tooth saw signal. Its frequency and sampling rate were set to $100 \mathrm{~Hz}$ and $10^{6}$ samples per second, respectively, leading to a resolution of $10^{4}$ samples for one signal ramp.

The tuning behavior of each diode laser, with regard to its current and temperature, is unique and was determined in a preliminary investigation as described by e.g., Teichert et al. [15]. For all three diode lasers the current was modulated from $0 \mathrm{~mA}$ to $120 \mathrm{~mA}$. The correlation between the modulated laser current and the wave number is non-linear and was determined using a Fabry-Perot interferometer (SA200-12B, Thorlabs), with free spectral range (FSR) of $1.5 \mathrm{GHz}$. By knowing the spectral position of at least one absorption peak in the modulated signal and the relative change in wave number, the measured signal can be transformed from time to the wave number domain. In Figs. 1-3, two calculated $\mathrm{H}_{2} \mathrm{O}$ spectra of the scanned wave number ranges for diode lasers $\mathrm{A}, \mathrm{B}$ and $\mathrm{C}$ are shown. One at flame conditions (straight lines) with a gas temperature of $T=1900 \mathrm{~K}$, absorption length $l_{a}=5 \mathrm{~cm}$ and $\mathrm{H}_{2} \mathrm{O}$ concentration of $\mathrm{c}_{\mathrm{H}_{2} \mathrm{O}}=25 \%$ by volume and the other at ambient air conditions (dotted lines) with $T=296 \mathrm{~K}, l_{a}=40 \mathrm{~cm}$ (diode $\mathrm{A}$ and $\mathrm{B}$ ) and $l_{a}=68 \mathrm{~cm}$ (diode $\mathrm{C}$ ) and $\mathrm{c}_{\mathrm{H}_{2} \mathrm{O}}=0.23 \%$ by volume.

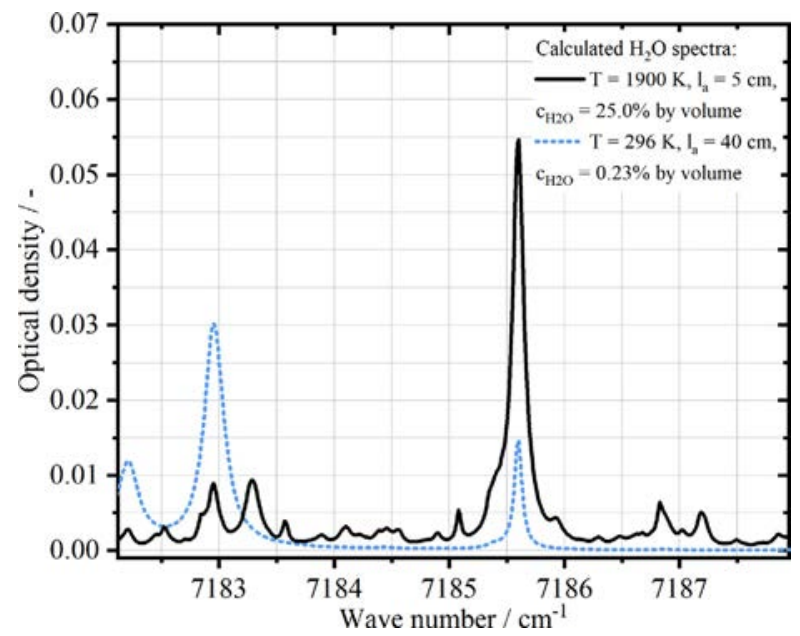

Fig. 2. Scanned wave number range of diode laser $B$, including calculated spectra at flame conditions ( $T=1900 \mathrm{~K}, l_{a}=5 \mathrm{~cm}$ and $c_{\mathrm{H}_{2} \mathrm{O}}=25 \%$ by volume $)$ and ambient conditions ( $T=296 \mathrm{~K}, l_{a}=40 \mathrm{~cm}$ and $c_{\mathrm{H}_{2} \mathrm{O}}=0.23 \%$ by volume)

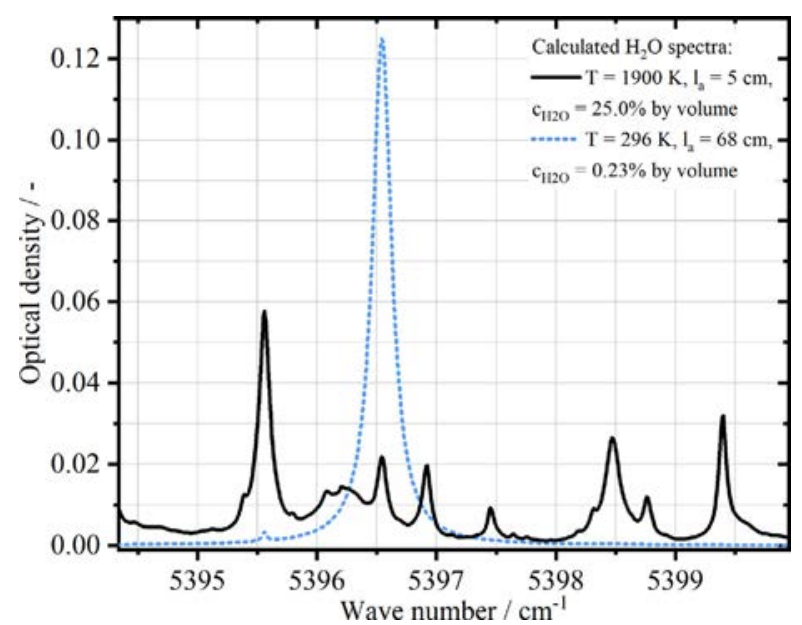

Fig. 3. Scanned wave number range of diode laser $C$, including calculated spectra at flame conditions ( $T=1900 \mathrm{~K}, l_{a}=5 \mathrm{~cm}$ and $c_{\mathrm{H}_{2} \mathrm{O}}=25 \%$ by volume $)$ and ambient conditions ( $T=298 \mathrm{~K}, l_{a}=68 \mathrm{~cm}$ and $c_{\mathrm{H}_{2} \mathrm{O}}=0.23 \%$ by volume $)$.

The schematic view of the laser setup is shown in Fig. 4. All three diode lasers were installed into laser mounts (LDM-4984, ILX Lightwave), which were controlled by a laser control unit (LDC 3908, ILX Lightwave). A multifunction I/O device (NI USB-6361, National Instruments), was used for both generation of the modulated saw tooth signal and the data acquisition of the measured detector signals. For diode laser A and B (Table 1) the same fiber optics (SMF28, Thorlabs), Collimator (CFC-8X-C, Thorlabs) and detector (PDA10CS-EC, Thorlabs) were used and alternated in operation. Both diode lasers were coupled using a fiber combiner (TW1550R2A1, Thorlabs) and split into the measurement and reference beam using a 50:50 beam splitter (TW1430R5A1, Thorlabs). The experimental setup for the third diode laser $C$, is similar to the first one, using components suitable for the selected wavelength range: fiber optics (SM2000, Thorlabs), 50:50 beam splitter (TW2000R5A1B, Thorlabs), collimator (F028APC-2000, Thorlabs) and detector (PDA10D, Thorlabs).

The beam profile of each collimated laser beam was measured using a PyroCam IV (Ophir Photonics, having $320 \times 320$ pixels and an effective pixel pitch of $80 \mu \mathrm{m})$, showing Gaussian profiles for all three diode lasers $\left(R^{2}\right.$ fit $\left.>0.998\right)$. The 10/90 knife-edge width $\mathrm{d}_{\mathrm{B}, 90}$ of the laser beam of diode laser A, B and $C$ were $1013 \mu \mathrm{m}$, $1207 \mu \mathrm{m}$ and $1671 \mu \mathrm{m}$, respectively. To further increase of the spa- 


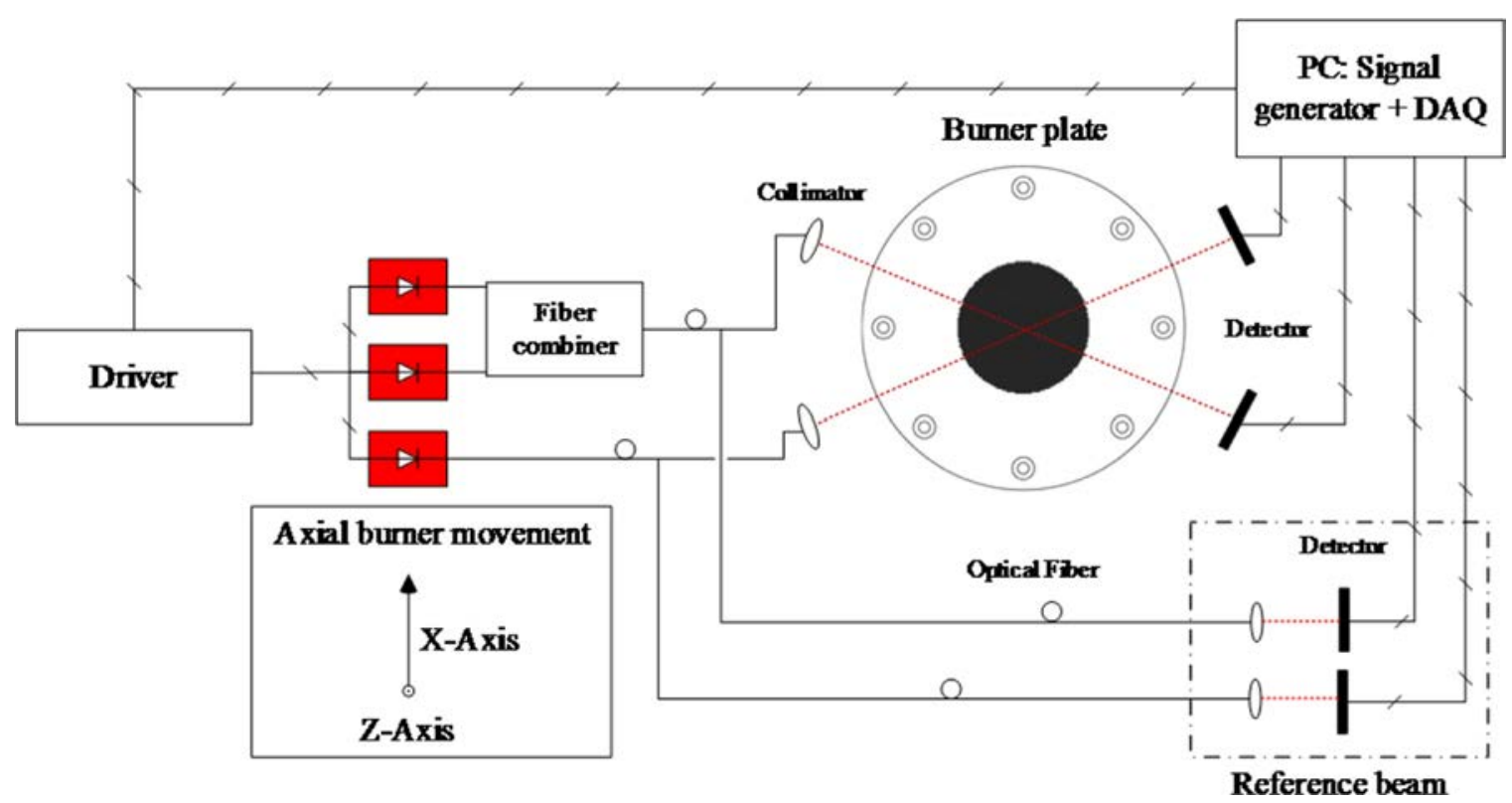

Fig. 4. Schematic view of the experimental setup, including the TDLAS setup and the burner plate of the Heat-Flux-Burner.

Table 2

Beam profile parameters and spatial resolution of the laser beam of diode $\mathrm{A}, \mathrm{B}$ and $\mathrm{C}$.

\begin{tabular}{lllll}
\hline Diode laser & $d_{\mathrm{B}, 90} / \mu \mathrm{m}$ & $d_{\mathrm{B}, \min } / \mu \mathrm{m}$ & $l_{\text {Rayleigh }} / \mathrm{mm}$ & $l_{\mathrm{B}, 25 \mathrm{~mm}} / \mu \mathrm{m}$ \\
\hline $\mathrm{A}$ & 1013 & 168 & 16 & 312 \\
$\mathrm{~B}$ & 1207 & 148 & 12 & 338 \\
$\mathrm{C}$ & 1671 & 140 & 9 & 416 \\
\hline
\end{tabular}

Table 3

Determined laminar burning velocities for all investigated flames at ambient pressure and a preheating temperature of $T_{\mathrm{P}}=300 \mathrm{~K}$

\begin{tabular}{lllllc}
\hline Flame & Ox. & $\phi$ & \multicolumn{3}{c}{ Laminar burning velocity $s_{L} / \mathrm{cm} / \mathrm{s}$} \\
\cline { 3 - 6 } & & & Exp. & CalTech2.3 & GRI3.0 \\
\hline P1 & $\mathrm{O}_{2}$ & 2.5 & 24.1 & 27.5 & 38.9 \\
P2 & $\mathrm{O}_{2}$ & 2.7 & 17.3 & 18.3 & 26.5 \\
P3 & $\mathrm{O}_{2}$ & 2.9 & 12.8 & 12.7 & 19.4 \\
A1 & Air & 0.77 & 23.1 & 22.3 & 25.5 \\
\hline
\end{tabular}

tial resolution, focusing lenses (LB1676-C, Thorlabs) were added to the setup. Table 2 lists the $90 \%$ beam diameter before the lens, the minimal diameter $d_{B, \min }$ of the beam waist (center of the burner plate), the characteristic Rayleigh length $l_{\text {Rayleigh }}$ and the beam diameter at the edge of the burner plate $l_{B, 25} \mathrm{~mm}$.

The absorption length was determined using a graphical analysis of images of the flames. Therefore, a CCD camera (mvBlueFox223 G, MatrixVision with $1360 \times 1024$ pixels) was used with a bandpass filter (FB430-10, Thorlabs) at $430 \pm 10 \mathrm{~nm}\left(\mathrm{CH}^{*}\right.$ chemiluminescence) to block the largest part of the soot radiation. The optical arrangement led to a spatial resolution of approximately $160 \mu \mathrm{m}$ by $180 \mu \mathrm{m}$.

An example of a Boltzmann plot, for a $\mathrm{CH}_{4} / \mathrm{O}_{2}$ flame (Table 3, P3) at $\mathrm{HAB}=7 \mathrm{~mm}$ is shown in Fig. 5 . Here, the calculated area terms of all investigated spectral lines (Table 1) are plotted against their lower-state energy $\mathrm{E}_{0}$ and fitted using a linear function. The calculation of error bars is described in Section 3.3.

\subsection{Burner setup}

All experiments were carried out using a Heat-Flux-Burner. The Heat-Flux-Method was developed by de Goy et al. [33] for measuring the laminar burning velocity and is described in detail in

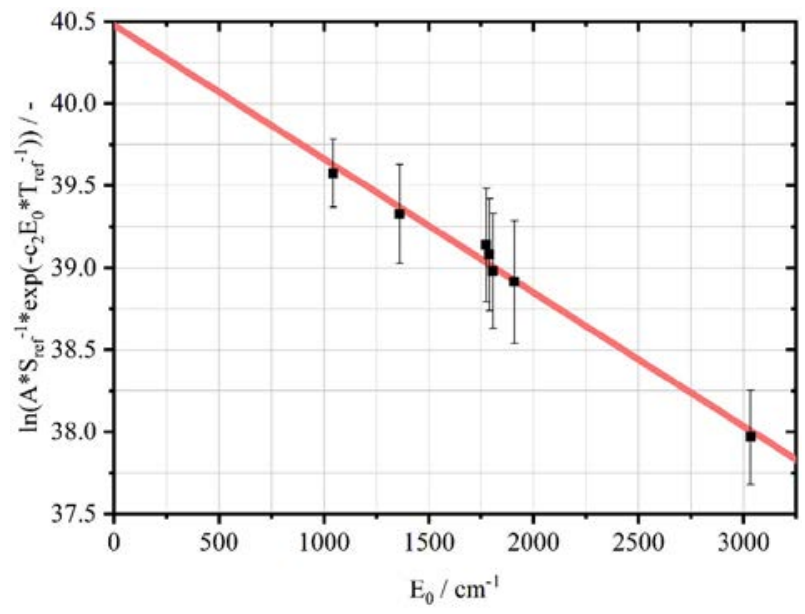

Fig. 5. Example of the Boltzmann plot analysis. The integrated area term [29] is plotted against the lower-state energy of a suitable spectral line and a linear fit is applied. This fit results in a temperature of $T=1868 \pm 117 \mathrm{~K}$.

$[33,34]$. The diameter and thickness of the burner plate are $50 \mathrm{~mm}$ and $2 \mathrm{~mm}$, respectively. For the determination of the temperature distribution inside the burner plate, ten type-E thermocouples distributed across the radius are used.

The burner was mounted on two linear axes (M-414.1DG, Physikalische Instrumente, repeatability of $1 \mu \mathrm{m}$ ) allowing vertical (Z-axis) and horizontal ( $X$-axis) movement of the burner, thus to a fixed position of the TDLAS setup.

The unburnt gases, methane and oxygen, were provided from bottles (purity of 99.95\%) and their flows were controlled with an accuracy of at least $1 \%$ using thermal mass flow controllers (Bronkhorst High-Tech). All inlet streams were conditioned to a temperature of $300 \mathrm{~K}$ (at ambient pressure) prior to entering the burner plenum.

\subsection{Data analysis}

Especially when investigating fuel rich (heavily sooting) flames, radiation and scattering cause disturbances in the measured detector signal, such as an offset (radiation) and a non-uniform gradient 


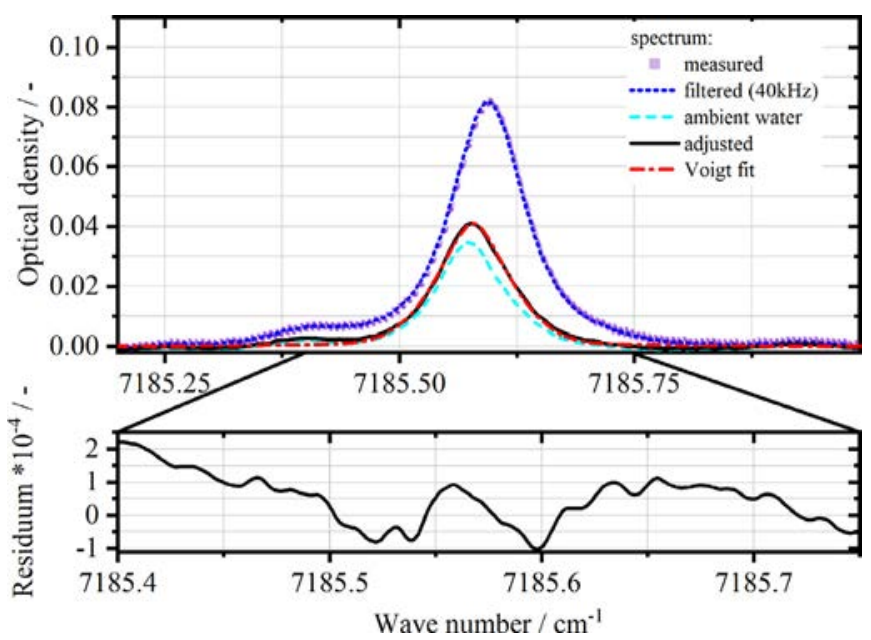

Fig. 6. Illustration (flame $\mathrm{A} 1$ at $\mathrm{HAB}=4 \mathrm{~mm}$, diode laser $\mathrm{B}$ ) of the determination of the final peak area. The adjusted spectrum (straight line) is calculated by subtracting humidity (dashed-dotted line) from the fitted spectrum (dotted line). A Voigt profile (dashed line) is fitted to the adjusted spectrum. The raw measurement signal (squares) is illustrated as a cloud of points. The residuum of this fit is shown in the lower graph.

(scattering) of the measured saw tooth signal. As a first step to improve the detector signal, a $40 \mathrm{kHz}$ low-pass filter was used to eliminate high frequencies. In advance, the signal was cut into 100 single signal ramps, which were normalized and analyzed independently. This includes the transformation from the time to the wave number domain, using information given by the Fabry-Perot interferometer, and the baseline fit resulting in the filtered spectrum (short-dotted line, Fig. 6). The measured raw signal is depicted as a cloud of points in Fig. 6.

This spectrum is a result of the water that is formed as a combustion product (with high concentrations at high temperature) and water from the humidity of the ambient air (low concentration at low temperature). Due to the experimental setup, the laser path through ambient air (absorption length) was eight (diode A and B) to 14 (diode $\mathrm{C}$ ) times longer than through the flame. Therefore, it is necessary to take the humidity of the air for each measurement into account using a reference beam to determine the spectrum formed by the humidity alone (dashed-dotted line, Fig. 6). Subsequently, the humidity spectrum was subtracted from the measurement spectrum, resulting in the final water spectrum (straight line, Fig. 6). Additionally, the edge region of the one-dimensional flame, where the gradients in temperature and concentration appear, was taken into account. Bosschaart et al. [35] determined this distance to be in the range of $5 \mathrm{~mm}$. The results show only minor influences ( $<5 \%$ of the peak area) on the signal. This uncertainty was taken into account in the data analysis, by subtracting an additional spectra at average temperature $\left(T_{\text {avg }}=\left(T_{\text {flame }}-T_{\text {ambient }}\right) / 2\right)$ with an absorption length of $10 \mathrm{~mm}$ (twice the edge area). In order to determine the peak area, a Voigt line shape was fitted to the final spectrum. The residuum of the fit is also illustrated on the bottom of Fig. 6 depicting a reasonably good quality of the fit (lower graph) in the center area of the absorption. At the periphery of the peak the absolute of the residuum increases because of the rising influence of additional absorption lines. Finally using the probability distribution, a weighted average was calculated for every measurement from the determined peak areas of 100 signal ramps. The whole procedure was repeated for all investigated absorption peaks at every HAB.

The fitting of all investigated peaks of diode $A$ and $C$ is depicted in Fig. 7. For the sake of clarity, only the adjusted spectrum and the according Voigt fits are plotted against the wave number.
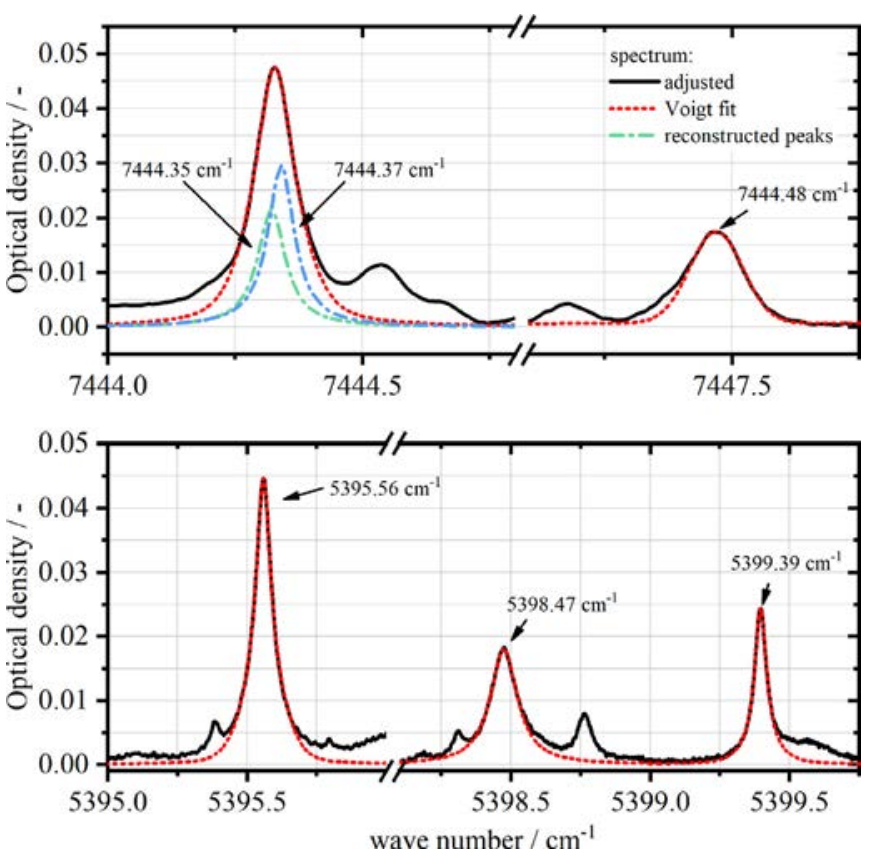

Fig. 7. Adjusted high temperature spectra (straight lines) and corresponding Voigt fits (dotted lines) for the investigated peaks of diode lasers A and C (flame A1 at $\mathrm{HAB}=4 \mathrm{~mm}$ ). In the upper graph the reconstruction of the two absorption peaks at $7444.35 \mathrm{~cm}^{-1}$ and $7444.37 \mathrm{~cm}^{-1}$ is depicted (dashed-dotted lines).

All peaks shown in Figs. 6 and 7 are results of flame A1 at $\mathrm{HAB}=4 \mathrm{~mm}$.

Using these average peak areas, the Boltzmann-plot analysis for the determination of temperature and, adding the additional information of the absorption length, the calculation of the water concentration was performed.

For the linear regression, the uncertainties in each point were considered using an error propagation, resulting in the final uncertainties in temperature and water concentration. This includes the uncertainties in the line intensity $S(T)$ and lower-state energy $E_{0}$ given by the applied databases, uncertainties from the line shape fit (Voigt) and the area distribution of all independently analyzed signal ramps for each $\mathrm{HAB}$.

\subsection{Numerical approach}

The investigated flames were numerically simulated as freely propagating flames using the PREMIX code [36] of the ANSYS Chemkin Pro 19.0 package.

Two chemical reaction mechanisms, GRI3.0 [37] (53 species and 544 reactions) and CalTech2.3 [38,39] (149 species and 1651 reactions), were used in this study. The CalTech2.3 was developed specifically for modeling the formation of soot precursors such as $\mathrm{C}_{2} \mathrm{H}_{2}, \mathrm{C}_{3} \mathrm{H}_{4}, \mathrm{C}_{3} \mathrm{H}_{6}, \mathrm{C}_{4} \mathrm{H}_{6}$ and PAH.

Approximately 300 grid points were used for the resolution of the reactor length of $10 \mathrm{~cm}$ for all calculations. Multicomponent and thermal diffusion were considered for the determination of the laminar burning velocities (Table 3 ), the temperature profiles and the $\mathrm{H}_{2} \mathrm{O}$-concentrations. The $\mathrm{CH}_{4}$ - and $\mathrm{O}_{2}$-feed were at standard inlet conditions.

\section{Results and discussion}

In this section, the experimental results are shown and discussed. In preceding investigations (Section 4.1), boundary conditions for the investigation of laminar quasi-adiabatic one-dimensional flames were experimentally determined and 


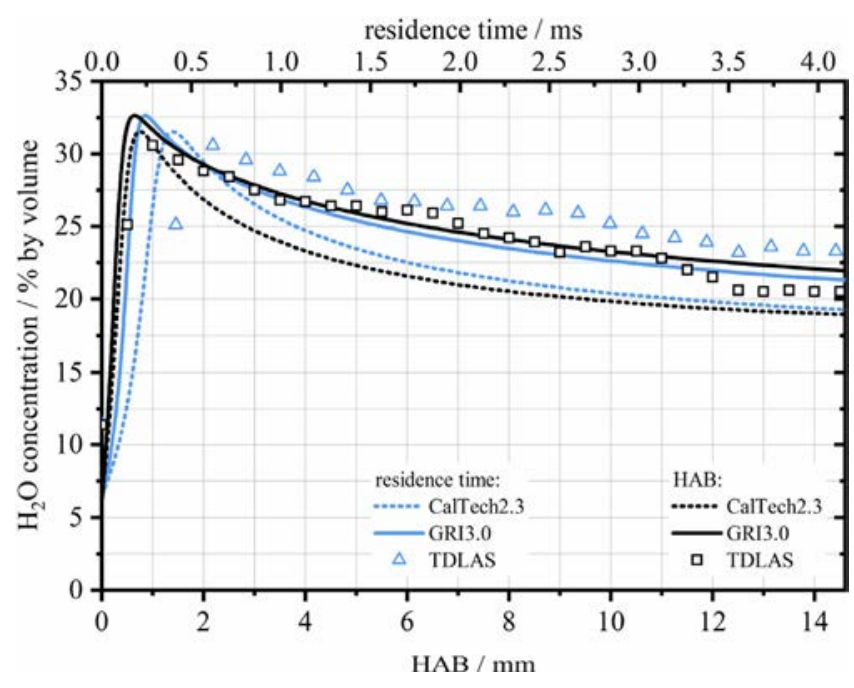

Fig. 8. Comparison of the water concentration profile of flame P1 between $H A B$ and residence time for the CalTech2.3 (dashed lines) and GRI3.0 (straight lines).

compared to numerical results. Additionally, the results obtained by the TDLAS system were validated, using a lean $\mathrm{CH}_{4}$ /air-flame.

Section 4.2 presents results for temperatures and species concentrations measured with the TDLAS system in the fuel-rich oxyfuel $\mathrm{CH}_{4}$ flames, which were the focus of this experimental study.

\subsection{Preliminary investigations}

As mentioned in Section 3, the major advantage of a HeatFlux-Burner is the possibility to stabilize one-dimensional quasiadiabatic flames. With this device, the laminar burning velocity $s_{L}$ of each equivalence ratio was determined separately in preliminary investigations. The results are shown in Table 3. The inlet conditions were used for further TDLAS investigations.

Comparing calculated and experimental $s_{L}$ major, differences are observed. In the case of flame P1, calculated burning velocities were obtained using the GRI3.0 and CalTech2.3 chemical kinetic schemes resulting in $s_{L}=38.9 \mathrm{~cm} / \mathrm{s}$ and $s_{L}=27.5 \mathrm{~cm} / \mathrm{s}$, respectively, which leads, in the case of this strongly fuel rich case, to a deviation of $61 \%$ between the experimental results and the calculations using GRI3.0. Due to the laminar burning velocity differences of both mechanism and experiments, the divergence of the residence time has to be considered in the comparison. In order to estimate the residence time of the experiments, numerical calculations with burner-stabilized reactor were performed using the CalTech2.3 mechanism. Here, the experimental inlet velocities and the measured temperature profile were used as boundary conditions as suggested by Lin et al. [40].

The water concentration profile is plotted against the HAB (bottom $X$-axis) and against residence time (top $X$-axis) of flame P1 in Fig. 8. The peak concentration is found in spatial coordinates at $\mathrm{HAB}=0.75 \mathrm{~mm}$ for both mechanisms. With respect to the residence time coordinate, a shift is observed using the CalTech2.3 mechanism (dashed lines), at which the maximum of the $\mathrm{H}_{2} \mathrm{O}$ concentration is reached $0.25 \mathrm{~ms}$ later in comparison to the results of the calculations with the GRI3.0 mechanism (straight lines). In the post flame zone ( $\mathrm{HAB}=10 \mathrm{~mm})$, the water concentrations differ by approximately $3.5 \%$ by volume between both mechanisms. In the time domain $\mathrm{HAB}=10 \mathrm{~mm}$ is reached after $2.4 \mathrm{~ms}$ using GRI3.0 and $3.4 \mathrm{~ms}$ using CalTech2.3. The difference in the $\mathrm{H}_{2} \mathrm{O}$ concentration between both mechanism in the time domain at $\tau=3 \mathrm{~ms}$ is $2.4 \%$ by volume, due to the faster decrease of the water concentration of the CalTec2.3. The experiments show in flame

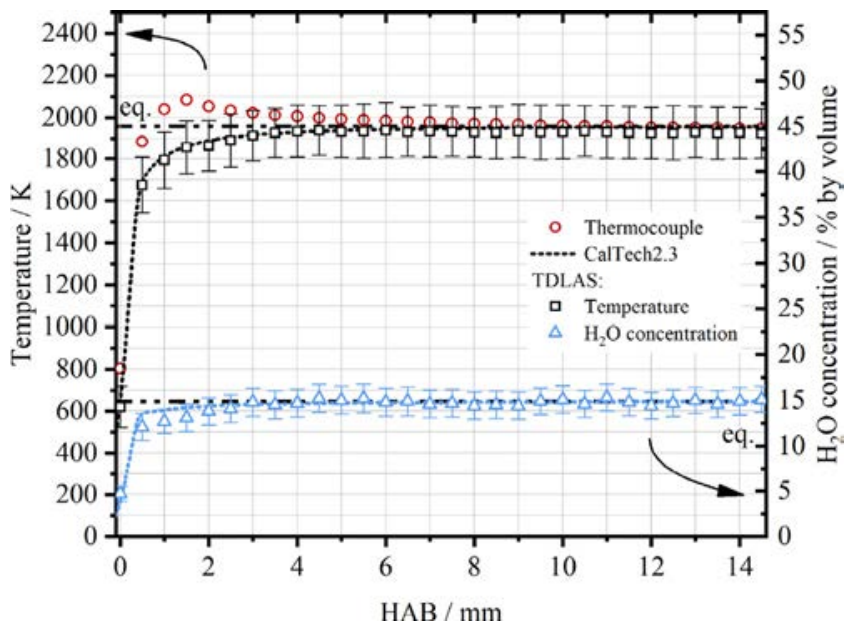

Fig. 9. Determination of temperature (left $y$-axis) and water concentration (right $y$ axis) profiles of flame A1, using thermocouple and TDLAS compared to calculated results.

P1 a slower decrease of the water concentration than both mechanism in time domain.

In order to assess the accuracy of the measurement system, a slightly lean methane/air flame (Table $3, \mathrm{~A} 1$ ) was investigated as a reference case. The profile of temperature was determined experimentally with two different diagnostic systems (TDLAS and thermocouple) and compared with calculation results. The case of a lean flame was selected to avoid any soot deposition on the thermocouple, which otherwise would distort the measured temperatures. Furthermore, the determined water concentration profile is compared with the calculated results in Fig. 9.

Both mechanisms, CalTech2.3 and GRI3.0, lead to almost identical results in temperature and water concentration profiles. For this reason, only the results of the CalTech2.3 mechanism are shown in Fig. 9. After a steep increase in the flame front, temperature and water concentration smoothly approach equilibrium conditions ( $T_{\mathrm{eq}}=1957 \mathrm{~K}, c_{\mathrm{eq}}=14.9 \%$ by volume).

One type-S (Pt-Rh) thermocouple was used for the invasive temperature measurements. The resolution of the axial temperature profiles was chosen densely with a step size of $0.5 \mathrm{~mm}$. The obtained data were corrected for radiation losses following the correction approach by Shaddix [41], using the emissivity values of $\varepsilon=0.22$ (Pt-Rh).

A significant difference between thermocouple measurements and calculated results was seen in the flame zone $(\mathrm{HAB}=1 \mathrm{~mm}$ to $\mathrm{HAB}=3 \mathrm{~mm}$ ), where measured temperatures overshoot the calculated by a maximum of $185 \mathrm{~K}(\mathrm{HAB}=1.5 \mathrm{~mm})$ and decreases to the calculated ones in the post flame zone. These differences can be attributed to the catalytic effect of the thermocouple material.

Temperatures measured using TDLAS corresponded well to the predicted ones with both mechanisms over the whole flame and the measured ones with thermocouple in the post flame zone $(\mathrm{HAB}>4 \mathrm{~mm})$. In contrast to the thermocouple measurements, an overshoot of the temperature in the flame zone cannot be identified which is in agreement with the numerical calculations.

In addition to the temperature, the water concentration profile was determined and compared to the calculated ones. While matching the calculated results perfectly at the first $H A B$ ( $\mathrm{HAB}=0 \mathrm{~mm}$ to $\mathrm{HAB}=2 \mathrm{~mm}$ ), the experimentally determined water concentrations are slightly higher than the calculated ones ( $\Delta c_{\max }=1.6 \%$ by volume), but well within the confidence interval in the post flame zone.

Overall, the results of the measurements of the reference case (flame A1) show that the experimental setup of the in-situ mea- 


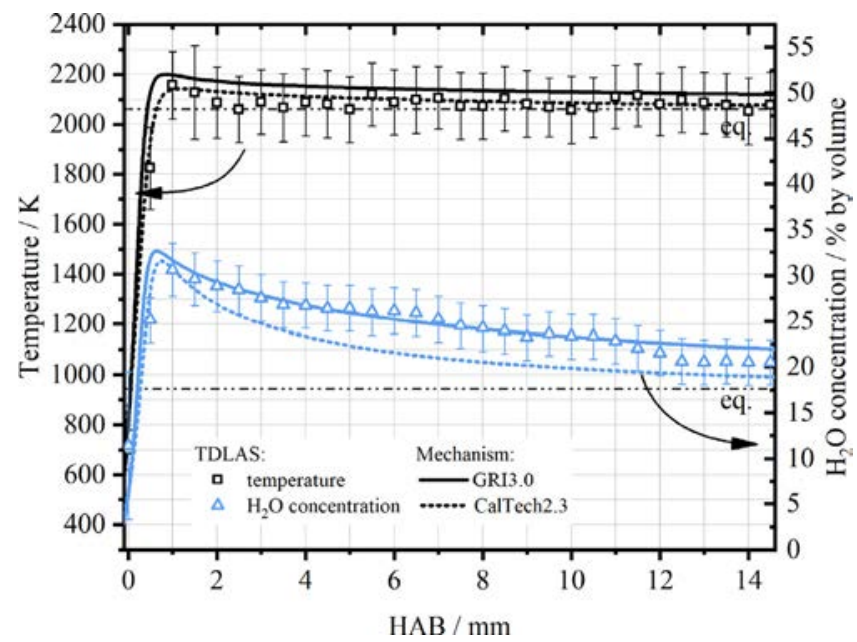

Fig. 10. Determination of temperature (left $y$-axis) and water concentration (right $y$-axis) profiles of flame P1 $(\phi=2.5)$, using TDLAS compared to calculated results.

surement technique TDLAS is suitable for the determination of temperature and water concentration profiles in premixed laminar flames.

\subsection{Investigation of oxy-fuel flames}

In the following section, measurement data of the oxy-fuel flames P1, P2 and P3 are presented and discussed in the following (Figs. 10-12). For each flame, the measured laminar burning velocity (Table 3 ) is used as the inlet velocity.

For all three figures, the temperature (left y-axis, black symbols and lines) and water concentration (right $y$-axis, gray symbols and lines) are plotted over the HAB. Experimental results are illustrated using symbols, while calculated results are displayed using dotted lines for the CalTech2.3 and dashed lines for the GRI3.0.

The results of flame P1 $(\phi=2.5)$ are shown in Fig. 10. Comparing the two mechanisms, several discrepancies can be identified under fuel-rich oxy-fuel conditions: regarding the temperature profile, a slightly steeper gradient in the temperature increase in the flame front ( $\mathrm{HAB}=0 \mathrm{~mm}$ to $\mathrm{HAB}=0.5 \mathrm{~mm}$ ) is calculated and slightly higher temperatures are predicted using the GRI3.0 mechanism. The temperature profile as determined experimentally using TDLAS correlates to the calculated results. The steep increase in temperature can be shown in three measured temperatures $(\mathrm{HAB}=0 \mathrm{~mm}$ to $\mathrm{HAB}=1.5 \mathrm{~mm})$ ending in the peak temperature. The measured values are slightly below the calculated ones in the post flame zone. In contrast to the results of lean $\mathrm{CH}_{4}$-air flame A1 (Fig. 9), a temperature overshoot above the equilibrium temperature (SAFT) is observed, as numerically predicted by Stelzner et al. [23].

Concerning the water concentration, the calculated results clearly differ in the decomposition of the water concentration in the post flame zone. While only slight differences in gradient of the $\mathrm{H}_{2} \mathrm{O}$ production and peak $\mathrm{H}_{2} \mathrm{O}$ concentration can be seen, the calculated water concentration decreases by $13 \%(\mathrm{HAB}=14.5 \mathrm{~mm})$ when using the CalTech2.3. However, both mechanisms predict an overshoot in the water concentration as well. The experimentally determined water concentrations are consistent with the GRI3.0 mechanism concerning water decomposition in the post flame zone.

For flame P1 the phenomenon of SAFT is determined experimentally with an overshoot in temperature $\left(\Delta T(P 1)=T_{\max }-T_{e q}=\right.$ $120 \mathrm{~K})$ and water concentration $\left(\Delta c_{\mathrm{H}_{2} \mathrm{O}}(P 1)=14 \%\right.$ by volume $)$.

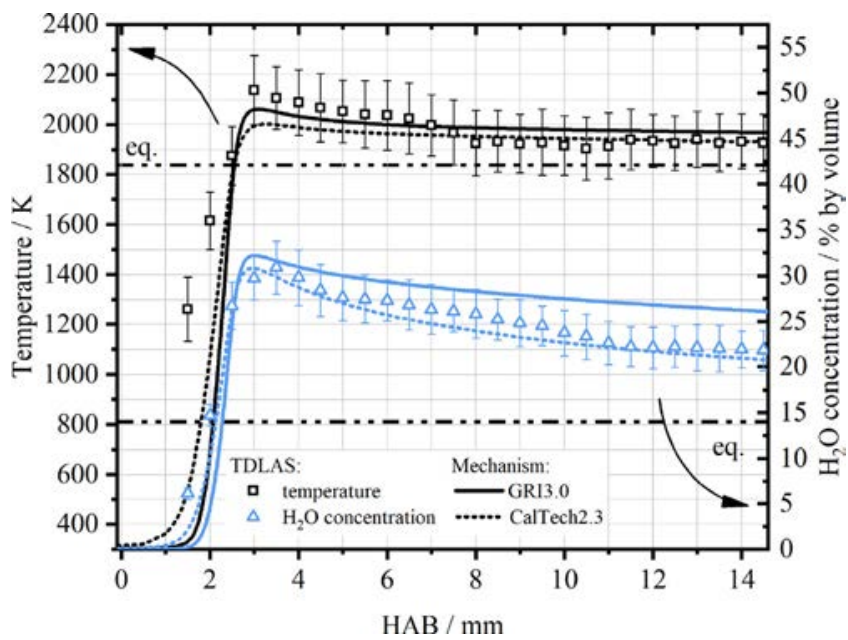

Fig. 11. Determination of temperature (left $y$-axis) and water concentration (right $y$-axis) profiles of flame P2 $(\phi=2.7)$, using TDLAS compared to calculated results.

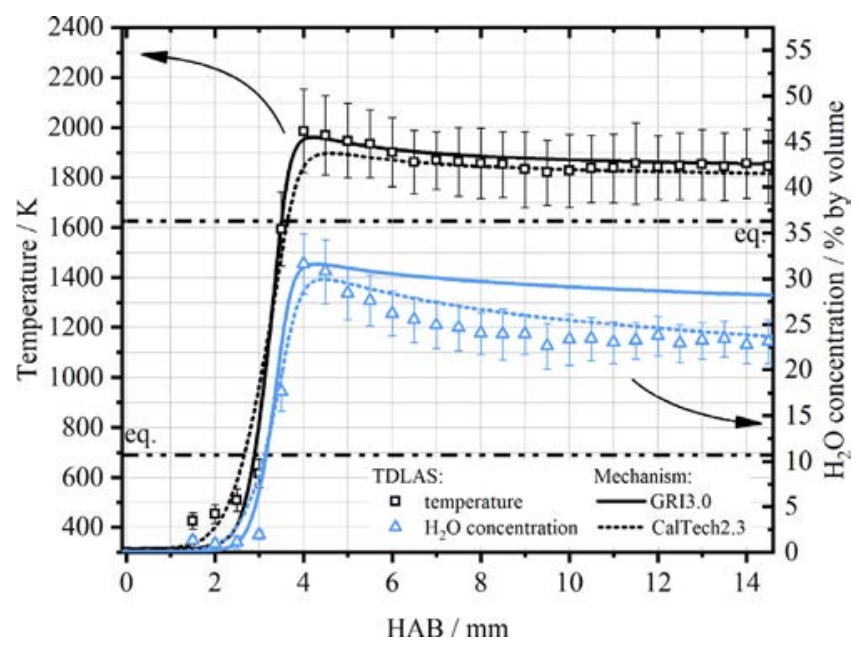

Fig. 12. Determination of temperature (left $y$-axis) and water concentration (right $y$-axis) profiles of flame P3 ( $\phi=2.9)$, using TDLAS compared to calculated results.

The results of the second flame P2 $(\phi=2.7)$ and third flame P3 $(\phi=2.9)$ are shown in Figs. 11 and 12, respectively. The tendencies of both mechanisms in terms of temperature and water concentrations are similar for both flames to flame P1. Moreover, with increasing equivalence ratio, the discrepancies of the two mechanisms increase when it comes to the decomposition of the water concentration.

For both flames P2 and P3, temperatures determined using TDLAS show a decreasing peak temperature for higher equivalence ratios. Despite this decrease an increase in the overshoot of the peak temperature $(\Delta T(P 2)=300 \mathrm{~K}$ and $\Delta T(P 3)=370 \mathrm{~K})$ is observed. This can be traced back to an even larger decrease in the equilibrium temperature while increasing the equivalence ratio. This fact indicates, that the time scale of the fast oxidations reactions remains almost constant, whereas the reactions of the endothermic formation of the synthesis gas slow down in the post flame zone. Contrary to flames P1 and P2, the experimentally measured temperatures for $\mathrm{P} 3$ differ in the slope of the temperature increase in the flame front. In the post flame zone, the measured results show slight deviations around the calculated results for flame P2 and P3.

Examining the experimentally determined water concentrations, the results show stronger overshoots with increasing $\phi$ $\left(\Delta c_{\mathrm{H}_{2} \mathrm{O}}(P 2)=16 \%\right.$ by volume and $\Delta c_{\mathrm{H}_{2} \mathrm{O}}(P 3)=21 \%$ by volume $)$. 


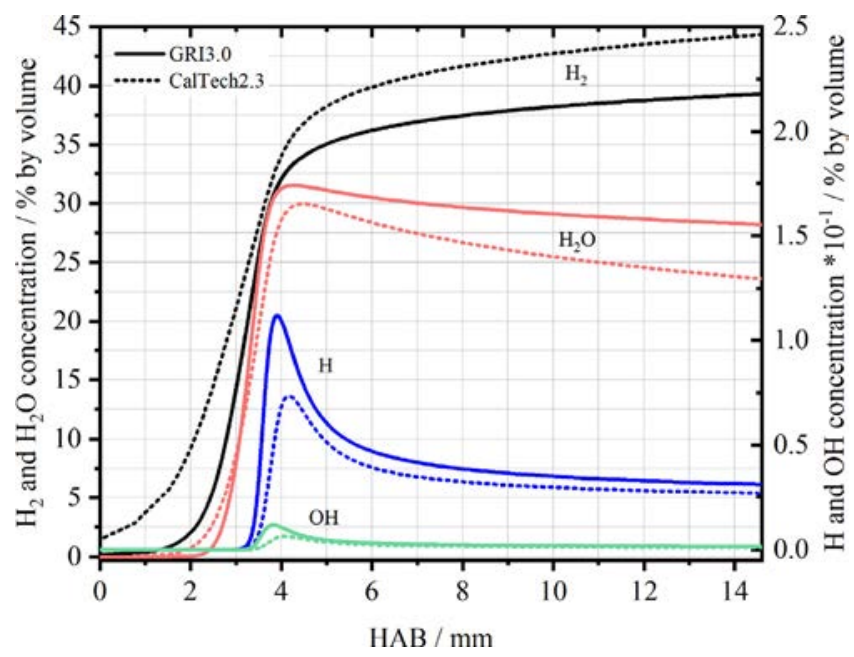

Fig. 13. Calculated concentration profiles for the reactants of $\mathrm{OH}+\mathrm{H}_{2} \leftrightarrow \mathrm{H}+\mathrm{H}_{2} \mathrm{O}$ for the GRI3.0 (straight lines) and CalTech2.3 (dotted lines) of flame P3. Left $y$-axis: molecules, right $y$-axis: radicals.

Contrary to the measured temperatures, the measured peak water concentration is almost constant, ranging between $30 \%$ and $32 \%$ by volume for all three investigated flames.

A shift can be observed, comparing experimentally and numerically determined water concentrations. In the case of P1, calculations with the GRI3.0 are aligned with the experimental results, whereas in the case of P2 and P3 the consistency between calculations and measurements is better for the CalTech2.3 mechanism.

In order to identify the differences between both mechanisms the rate of production (ROP) and sensitivity analysis of $\mathrm{H}_{2} \mathrm{O}$, with emphasis on the post flame zone, were performed.

The sensitivity analysis for $\mathrm{H}_{2} \mathrm{O}$ showed 130 reactions sensitive for the $\mathrm{H}_{2} \mathrm{O}$ formation in the case of the GRI3.0 and 220 reactions for the CalTech2.3.

The ROP drops to its minimum in the post flame zone where it differs almost by a factor of two, with the CalTech2.3 predicting lower values. Downstream of its minimum the ROP increase for both mechanisms, where the CalTech2.3 again shows lower values of the ROP over the entire investigated range. This indicates the more pronounced decomposition of $\mathrm{H}_{2} \mathrm{O}$ in the case of the CalTech2.3.

With a share of more than 93\% (CalTech2.3) and 85\% (GRI3.0) the reaction of $\mathrm{OH}+\mathrm{H}_{2} \leftrightarrow \mathrm{H}+\mathrm{H}_{2} \mathrm{O}$ in reverse direction is mainly responsible for the $\mathrm{H}_{2} \mathrm{O}$ decomposition in the post flame zone for both mechanisms. A comparison of the reaction rates $k$ of this reaction showed almost identical results for both mechanisms. Therefore, all species participating in this reaction were further investigated.

Figure 13 shows the concentration profiles of all four reactants as a function of HAB for the GRI3.0 (straight lines) and the CalTech2.3 (dotted lines). In the flame zone, the total ROP of all shown reactants is greater for the GRI3.0, due to the steeper gradients in the concentration profiles.

In the post flame zone ( $\mathrm{HAB} \geq 4 \mathrm{~mm}$ ), the Caltech2.3 predicts lower concentrations, except for $\mathrm{H}_{2}$, over the entire investigated range and hence indicates a faster formation of the $\mathrm{H}_{2} / \mathrm{CO}$-.rich synthesis gas. The differences between the CalTech2.3 and the GRI3.0 are in the range of $6-12 \%, 9-15 \%, 13--38 \%$ and $29-41 \%$ for $\mathrm{H}_{2}, \mathrm{H}_{2} \mathrm{O}, \mathrm{H}$ and $\mathrm{OH}$ respectively.

The main difference between both mechanisms is observed in the decomposition of the OH-radical. Since CalTech2.3 was developed specifically for modeling the formation of soot precursors many reactions of the $\mathrm{C}_{1^{-}}, \mathrm{C}_{2^{-}}, \mathrm{C}_{3^{-}}, \mathrm{C}_{4^{-}}$and $\mathrm{PAH}$-pathways

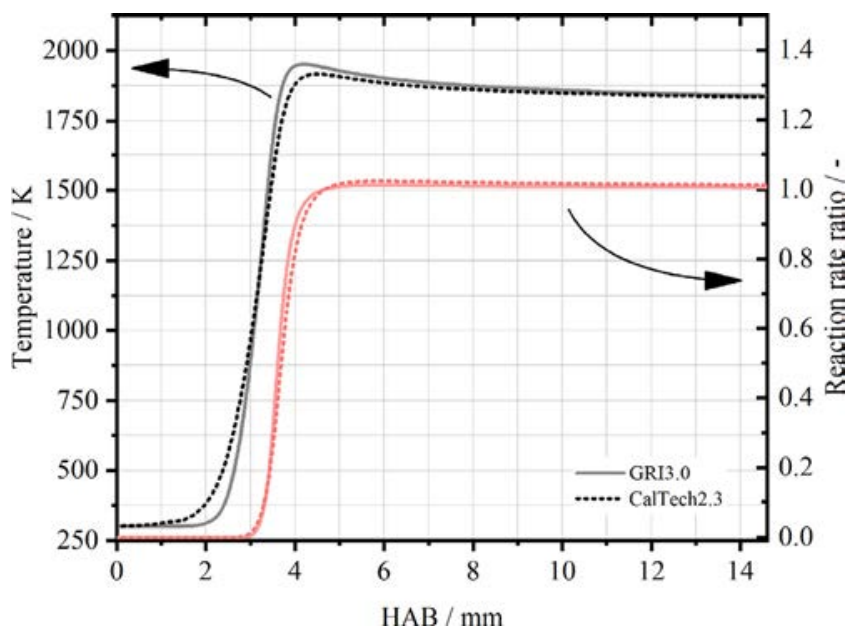

Fig. 14. Comparison of calculated temperature profiles (left $y$-axis) and reaction rate ratios (right $y$-axis) of $\mathrm{OH}+\mathrm{H}_{2} \leftrightarrow \mathrm{H}+\mathrm{H}_{2} \mathrm{O}$ for the GRI3.0 (straight lines) and the CalTech2.3 (dotted lines), flame P3.

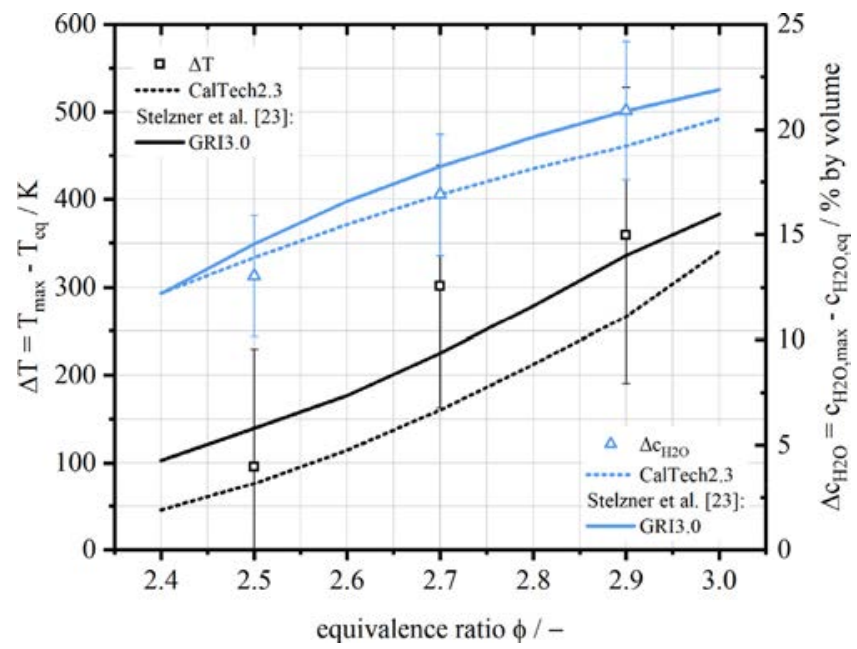

Fig. 15. Comparison of experimental (symbols) and numerical results (lines) by Stelzner et al. [23] and CalTech2.3 mechanism of SAFT (temperature on the left $y$ axis and water concentration on the right $y$-axis) in ultra-rich $\mathrm{CH}_{4} / \mathrm{O}_{2}$-flames.

consume OH-radicals. For the GRI3.0, only isolated reactions of higher hydrocarbons are included. Furthermore, the reaction rates and ROP for reactions, taken into account by both mechanisms, vary strongly. In the case of the dominant reaction for the decomposition of $\mathrm{OH}$ for both mechanisms of $\mathrm{C}_{2} \mathrm{H}_{2}+\mathrm{OH} \leftrightarrow \mathrm{CH}_{2} \mathrm{CO}+\mathrm{H}$ the reaction rate predicted by the CalTech2.3 is approximately $20 \%$ higher than by the GRI3.0 and the ROP four times larger for the CalTech2.3 in the post flame zone.

Figure 14 shows temperature profiles (left y-axis) and reaction rate ratio RRR of $\mathrm{OH}+\mathrm{H}_{2} \leftrightarrow \mathrm{H}+\mathrm{H}_{2} \mathrm{O}$ (right $y$-axis) for the GRI3.0 (straight lines) and CalTech2.3 (dotted lines) of flame P3. The RRR is defined as the coefficient of the backward $r_{b}$ and forward $r_{f}$ reaction rate: $R R R=r_{b} / r_{f}$. The elementary reaction is in partial equilibrium $(R R R=1)$ in the post flame zone for both mechanisms. The decomposition of the $\mathrm{H}_{2} \mathrm{O}$ molecule is forced more using the CalTech2.3 than the GRI3.0 mechanism, since both mechanisms show partial equilibrium in the post flame zone.

The experimentally determined values of SAFT in all investigated flames P1-P3 are shown in Fig. 15 and compared with the numerical results by Stelzner et al. [23] and the results of the 
CalTech2.3 mechanism. The temperatures from the experiments (Fig. 15, black squares) resemble the tendency of increasing SAFT with increasing equivalence ratio, as observed by both mechanisms (black lines).

Whereas the difference in $\Delta \mathrm{T}$ between the results by Stelzner et al. [23] and experimental results is below $45 \mathrm{~K}$ for flame P1 $(\phi=2.5)$ and P3 $(\phi=2.9)$, the largest difference is observed at P2 $(\phi=2.7)$, where the measured $\Delta T$ exceeds the calculated by $70 \mathrm{~K}$. Over the entire investigated range, SAFT predicted by the Caltech2.3 is approximately $65 \mathrm{~K}$ lower than for the GRI3.0. Comparing the experimentally (dots) and numerically (line) determined water concentration overshoot $\left(\Delta \mathrm{c}_{\mathrm{H}_{2} \mathrm{O}}\right)$, the largest difference again occurs at flame P2 with an experimental value of $1.5 \%$ by volume below the numerical results (GRI3.0). The smallest difference $(0.02 \%$ by volume) can be observed in the case of flame P2 (CalTech2.3).

The measured peak concentrations of water slightly increase from flame P1 (Fig. 10) to flame P3 (Fig. 12) from $30 \%$ by volume $(\phi=2.5)$ to $32 \%$ by volume $(\phi=2.9)$. This is accompanied by a drop in the equilibrium concentration from $18 \%$ by volume $(\phi=2.5)$ to $11 \%$ by volume $(\phi=2.9)$. A similar effect is observed for the temperature: a slight drop in the measured peak temperatures from $2180 \mathrm{~K}(\phi=2.5)$ to $1994 \mathrm{~K}(\phi=2.9)$ and a larger decrease in the equilibrium temperature $2061 \mathrm{~K}(\phi=2.5)$ to $1627 \mathrm{~K}$ $(\phi=2.9)$. This similarity can be taken as an indication for the fact that the increase in SAFT with higher equivalence ratios is mainly driven by the decrease in the equilibrium state (temperature and water concentration).

\section{Conclusion}

The in-situ measurement technique TDLAS was successfully applied for the determination of temperature and water concentration profiles in laminar, premixed, fuel-rich, quasi-adiabatic $\mathrm{CH}_{4} / \mathrm{O}_{2}$-flames at equivalence ratios $\phi>2.5$.

The TDLAS setup was successfully validated at a lean $\mathrm{CH}_{4} /$ airflame ( $\phi=0.77)$ comparing temperatures measured using thermocouples and TDLAS and calculated using the GRI3.0 and CalTech2.3 mechanisms.

The results for all three investigated POX-flames show that in the case of premixed fuel-rich $\mathrm{CH}_{4} / \mathrm{O}_{2}$-flames both reaction mechanisms show a similar trend in the decrease of the temperature in the post flame zone and correspond to the measured temperature using TDLAS. In contrast, the calculated decomposition of water in the post flame zone strongly depends on the applied chemistry scheme. Here, the CalTech2.3 mechanism showed excellent performance in comparison with the experimental data for flames P2 and P3. In the case of the least rich POX flame P1 $(\phi=2.5)$ investigated in this study the GRI3.0 mechanism showed a better performance.

A thorough analysis of both reaction mechanisms showed, that differences in the decomposition of the $\mathrm{H}_{2} \mathrm{O}$ may be traced back to the included soot precursor chemistry of the CalTech2.3 in general and on the faster consumption of the $\mathrm{OH}$-radical in particular.

The phenomenon of SAFT in fuel-rich oxy-fuel flames and its dependency on the equivalence ratio, as numerically predicted by Stelzner et al. [23] was experimentally determined using the local temperature and $\mathrm{H}_{2} \mathrm{O}$ concentration as markers.

\section{Declaration of Competing Interest}

The authors declare that they have no known competing financial interests or personal relationships that could have appeared to influence the work reported in this paper.

\section{Acknowledgments}

The present research work contributes to the Research Field Energy of Helmholtz Association (HGF).

\section{References}

[1] C.E. Baukal, Oxygen-enhanced combustion, CRC Press, Boca Raton, Fla, 1998

[2] Q. Li, T. Wang, Y. Liu, D. Wang, Experimental study and kinetics modeling of partial oxidation reactions in heavily sooting laminar premixed methane flames, Chem. Eng. J. 207-208 (2012) 235-244.

[3] A. Farooq, J.B. Jeffries, R.K. Hanson, In situ combustion measurements of H2O and temperature near $2.5 \mu \mathrm{m}$ using tunable diode laser absorption, Meas. Sci. Technol. 19 (2008) 75604.

[4] S. Li, A. Farooq, R.K. Hanson, H 2 o temperature sensor for low-pressure flames

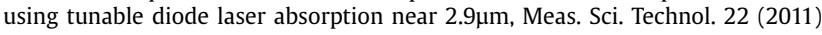
125301.

[5] S. Wagner, M. Klein, T. Kathrotia, U. Riedel, T. Kissel, A. Dreizler, V. Ebert, In situ TDLAS measurement of absolute acetylene concentration profiles in a non-premixed laminar counter-flow flame, Appl. Phys. B 107 (2012) 585-589.

[6] Y. Ögren, A. Sepman, Z. Qu, F.M. Schmidt, H. Wiinikka, Comparison of measurement techniques for temperature and soot concentration in premixed, small-scale burner flames, Energy Fuels 31 (2017) 11328-11336.

[7] J. Houston Miller, S. Elreedy, B. Ahvazi, F. Woldu, P. Hassanzadeh, Tunable diode-laser measurement of carbon monoxide concentration and temperature in a laminar methane-air diffusion flame, Appl. Opt. 32 (1993) 6082-6089.

[8] C.S. Goldenstein, I.A. Schultz, R.M. Spearrin, J.B. Jeffries, R.K. Hanson, Scanned-wavelength-modulation spectroscopy near $2.5 \mu \mathrm{m}$ for $\mathrm{H} 2 \mathrm{O}$ and temperature in a hydrocarbon-fueled scramjet combustor, Appl. Phys. B 116 (2014) 717-727.

[9] Z Qu, R. Ghorbani, D. Valiev, F.M. Schmidt, Calibration-free scanned wavelength modulation spectroscopy-application to $\mathrm{H}(2) \mathrm{O}$ and temperature sensing in flames, Opt. Express 23 (2015) 16492-16499.

[10] Z. Qu, F.M. Schmidt, In situ H2O and temperature detection close to burning biomass pellets using calibration-free wavelength modulation spectroscopy, Appl. Phys. B 119 (2015) 45-53.

[11] G.B. Rieker, J.B. Jeffries, R.K. Hanson, Calibration-free wavelength-modulation spectroscopy for measurements of gas temperature and concentration in harsh environments, Appl. Opt. 48 (2009) 5546-5560.

[12] K. Sun, R. Sur, X. Chao, J.B. Jeffries, R.K. Hanson, R.J. Pummill, K.J. Whitty, TDL absorption sensors for gas temperature and concentrations in a high-pressure entrained-flow coal gasifier, Proc. Combust. Inst. 34 (2013) 3593-3601.

[13] A. Sepman, Y. Ögren, M. Gullberg, H. Wiinikka, Development of TDLAS sensor for diagnostics of $\mathrm{CO}, \mathrm{H} 2 \mathrm{O}$ and soot concentrations in reactor core of pilot-scale gasifier, Appl. Phys. B 122 (2016) 89.

[14] R. Sur, K. Sun, J.B. Jeffries, J.G. Socha, R.K. Hanson, Scanned-wavelength-modulation-spectroscopy sensor for $\mathrm{CO}, \mathrm{CO}_{2}, \mathrm{CH}_{4}$ and $\mathrm{H}_{2} \mathrm{O}$ in a high-pressure engineering-scale transport-reactor coal gasifier, Fuel 150 (2015) 102-111.

[15] H. Teichert, T. Fernholz, V. Ebert, Simultaneous in situ measurement of CO, $\mathrm{H}_{2} \mathrm{O}$, and gas temperatures in a full-sized coal-fired power plant by near-infrared diode lasers, Appl. Opt. 42 (2003) 2043.

[16] X. Liu, Line-of-sight absorption of H2O vapor: gas temperature sensing in uniform and nonuniform flows, (dissertation), Mechanical Engineering, Stanford.

[17] N.A. Slavinskaya, U. Riedel, S.B. Dworkin, M.J. Thomson, Detailed numerica modeling of PAH formation and growth in non-premixed ethylene and ethane flames, Combust. Flame 159 (2012) 979-995.

[18] E. Meeks, R.J. Kee, D.S. Dandy, M.E. Coltrin, Computational simulation of diamond chemical vapor deposition in premixed $\mathrm{C}_{2} \mathrm{H}_{2} / \mathrm{O}_{2} / \mathrm{H}_{2}$ and $\mathrm{CH}_{4} \mathrm{O}_{2}$-strained flames, Combust. Flame 92 (1993) 144-160.

[19] K.E. Bertagnolli, R.P. Lucht, Temperature profile measurements in stagnation-flow, diamond-forming flames using hydrogen cars spectroscopy, Symp. (Int.) Combust. 26 (1996) 1825-1833

[20] K.E. Bertagnolli, R.P. Lucht, M.N. Bui-Pham, Atomic hydrogen concentration profile measurements in stagnation-flow diamond-forming flames using three-photon excitation laser-induced fluorescence, J. Appl. Phys. 83 (1998) 2315-2326.

[21] F. Liu, H. Guo, G.J. Smallwood, Ö.L. Gülder, Numerical study of the superadiabatic flame temperature phenomenon in hydrocarbon premixed flames, Proc. Combust. Inst. 29 (2002) 1543-1550.

[22] F. Liu, Ö.L. Gülder, Effects of $\mathrm{H} 2$ and h preferential diffusion and unity Lewis number on superadiabatic flame temperatures in rich premixed methane flames, Combust. Flame 143 (2005) 264-281.

[23] B. Stelzner, C. Weis, P. Habisreuther, N. Zarzalis, D. Trimis, Super-adiabatic flame temperatures in premixed methane flames, Fuel 201 (2017) 148-155.

[24] C.S. Goldenstein, R.M. Spearrin, J.B. Jeffries, R.K. Hanson, Infrared laser-absorption sensing for combustion gases, Prog. Energy Combust. Sci. 60 (2017) 132-176.

[25] M.A. Bolshov, Y.A. Kuritsyn, Y.V. Romanovskii, Tunable diode laser spectroscopy as a technique for combustion diagnostics, Spectrochim. Acta B: Atom. Spectrosc. 106 (2015) 45-66.

[26] C.S. Goldenstein, C.L. Strand, I.A. Schultz, K. Sun, J.B. Jeffries, R.K. Hanson, Fitting of calibration-free scanned-wavelength-modulation spectroscopy spectra for determination of gas properties and absorption lineshapes, Appl. Opt. 53 (2014) 356-367. 
[27] L.S. Rothman, I.E. Gordon, Y. Babikov, A. Barbe, D. Chris Benner, P.F. Bernath, M. Birk, L. Bizzocchi, V. Boudon, L.R. Brown, A. Campargue, K. Chance, E.A. Cohen, L.H. Coudert, V.M. Devi, B.J. Drouin, A. Fayt, J.-.M. Flaud, R.R. Gamache, J.J. Harrison, J.-.M. Hartmann, C. Hill, J.T. Hodges, D. Jacquemart, A. Jolly, J. Lamouroux, R.J. Le Roy, G. Li, D.A. Long, O.M. Lyulin, C.J. Mackie, S.T. Massie, S. Mikhailenko, H.S.P. Müller, O.V. Naumenko, A.V. Nikitin, J. Orphal, V. Perevalov, A. Perrin, E.R. Polovtseva, C. Richard, M.A.H. Smith, E. Starikova, K. Sung, S. Tashkun, J. Tennyson, G.C. Toon, V.G. Tyuterev, G. Wagner, The HITRAN2012 molecular spectroscopic database, J. Quant. Spectrosc. Radiat. Transf. 130 (2013) 4-50.

[28] L.S. Rothman, I.E. Gordon, R.J. Barber, H. Dothe, R.R. Gamache, A. Goldman, V.I. Perevalov, S.A. Tashkun, J. Tennyson, HITEMP, the high-temperature molecular spectroscopic database, J. Quant. Spectrosc. Radiat. Transf. 111 (2010) 2139-2150.

[29] D.L. Barone, Investigation of TDLAS measurements in a scramjet engine, Cincinnati (2010).

[30] S. Wagner, Ortsaufgelöste in situ bestimmung absoluter $\mathrm{CH}_{4}, \mathrm{H}_{2} \mathrm{O}, \mathrm{OH}$, $\mathrm{CO}$ und $\mathrm{C}_{2} \mathrm{H}_{2}$ profile in laminaren gegenstromflammen mittels diodenlaser- und cavityring-down-spektroskopie, Dipl. Phys. Dissertation, Heidelberg.

[31] C.S. Goldenstein, R.M. Spearrin, J.B. Jeffries, R.K. Hanson, Wavelength-modulation spectroscopy near $2.5 \mu \mathrm{m}$ for $\mathrm{H}_{2} \mathrm{O}$ and temperature in high-pressure and -temperature gases, Appl. Phys. B 116 (2014) 705-716.

[32] C.S. Goldenstein, J.B. Jeffries, R.K. Hanson, Diode laser measurements of linestrength and temperature-dependent lineshape parameters of $\mathrm{H}_{2} \mathrm{O}-, \mathrm{CO}_{2}$-, and $\mathrm{N}_{2}$-perturbed $\mathrm{H}_{2} \mathrm{O}$ transitions near 2474 and $2482 \mathrm{~nm}$, J. Quant. Spectrosc. Radiat. Transf. 130 (2013) 100-111.
[33] L.P.H. de Goey, A. van Maaren, R.M. Quax, Stabilization of adiabatic premixed laminar flames on a flat flame burner, Combust. Sci. Technol. 92 (1993) 201-207.

[34] K. Bosschaart, Detailed analysis of the heat flux method for measuring burning velocities, Combust. Flame 132 (2003) 170-180.

[35] K.J. Bosschaart, M. Versluis, R. Knikker, T.H. Vandermeer, K.R.A.M. Schreel, L.P.H. de Goey, A.A. Van Steenhoven, The heat flux method for producing burner stabilized adiabatic flames: an evaluation with cars thermometry, Combust. Sci. Technol. 169 (2001) 69-87.

[36] R.J. Kee, J.F. Grcar, M.D. Smooke, J.A. Miller, PREMIX, Report No. SAND85-8240, 1985.

[37] G.P. Smith, D.M. Golden, M. Frenklach, N.W. Moriarty, B. Eiteneer, M. Goldenberg, C. Thomas Bowman, R.K. Hanson, S. Song, W.C.G. JR., V.V. Lissianski, Zhiwei Q., GRI30 Mechanism, http://www.me.berkeley.edu/gri_mech/.

[38] G. Blanquart, P. Pepiot-Desjardins, H. Pitsch, Chemical mechanism for high temperature combustion of engine relevant fuels with emphasis on soot precursors, Combust. Flame 156 (2009) 588-607.

[39] K. Narayanaswamy, G. Blanquart, H. Pitsch, A consistent chemical mechanism for oxidation of substituted aromatic species, Combust. Flame 157 (2010) 1879-1898.

[40] H. Lin, C. Gu, J. Camacho, B. Lin, C. Shao, R. Li, H. Gu, B. Guan, H. Wang, Z. Huang, Mobility size distributions of soot in premixed propene flames, Combust. Flame 172 (2016) 365-373.

[41] C.R. Shaddix, 33rd National Heat Transfer Conference (1999). 
Karlsruher Institut für Technologie

\section{Repository KITopen}

Dies ist ein Postprint/begutachtetes Manuskript.

Empfohlene Zitierung:

Sentko, M. M.; Schulz, S.; Stelzner, B.; Anderlohr, C.; Vicari, M.; Trimis, D.

Determination of temperature and water-concentration in fuel-rich oxy-fuel methane flames applying TDLAS. 2020. Combustion and flame, 214. doi: $10.5445 / I R / 1000105650$

Zitierung der Originalveröffentlichung:

Sentko, M. M.; Schulz, S.; Stelzner, B.; Anderlohr, C.; Vicari, M.; Trimis, D.

Determination of temperature and water-concentration in fuel-rich oxy-fuel methane flames applying TDLAS.

2020. Combustion and flame, 214, 336-345.

doi:10.1016/j.combustflame.2020.01.003

Lizenzinformationen: $\underline{\text { CC BY-NC-ND } 4.0}$ 